\title{
THE NEW WORLD 2020: A CRUCIAL PARADIGM FOR MEETING FAST CHANGING WORLD DEMANDS IN PAKISTAN AFTER COVID-19 OUTBREAK
}

\author{
Sana Rehman ${ }^{1}$, Ahmed Muzammil $^{2}$ \& Umi Lela ${ }^{1}$ \\ ${ }^{1}$ Humanities and Social Sciences Department, GIFT University, Gujranwala, Pakistan \\ ${ }^{2}$ Department of Dental Hygiene, College of Applied Health Sciences in Al Rass, Qassim University, \\ Al-Qassim Region, Saudi Arabia
}

received: 24.9.2020;

revised: 17.10.2020;

accepted: 7.11 .2020

\section{SUMMARY}

The waves of COVID-19 has shaken the world and bring about many changes in society. The changed environment or new world 2020 after COVID-19 pandemic demand high quality protection in all arena of life. The most important arena that require significant changes have been divided into four categories. First of all, the high mental health issues and low mental health services in Pakistan are not sufficient to control the mental health problem ratio. There is a need to develop more mental health services with trans-formative changes to mitigate the obnoxious post-pandemic effects. Secondly, the implementation of online therapeutic interventions must be available prior or after pandemic situation. Thirdly, as the pharmacy and mental health services in Pakistan are not capable to meet the international standards to provide patient care. Therefore, the advanced researchers are needed to investigate the fractures and gaps in social, economic and health care systems. Fourthly the provision of mental health support for children is a key area that needs considerable attention after pandemic or crises. The study has contemporary significance as disasters, crises and communicable disease has been prevalent throughout human history and may attack the world at any time in the future.

Key words: COVID-19 - Pakistan - New World 2020

\section{INTRODUCTION}

The COVID-19 outbreak due to SARS-CoV-2 fallout at China in December 2019 and has spread in 209 countries of Europe, Asia, Australia, and America including Pakistan (Waris et al. 2020). According to WHO (2020), (World Health Organization 2020) till May around 10, 3,925,815 confirmed cases of COVID-19 and 274,488 deaths have been recorded. The first case of COVID-19 in Pakistan was reported on February 26, 2020 (Government of Pakistan 2020). Till July 17, nearly 259,999 confirmed cases, and 5475 deaths had taken place in Pakistan (Worldometer 2020).

The COVID-19 not merely affected the physical health of the people, but also imparted the negative impact on mental health. The impact of COVID-19 on business due to lock down restrictions, shaked the sense of security and imparted a huge alteration in traditional lifestyle of public at large. The waves of COVID-19 shaked the world and bring about many changes in society. The changed environment or new world 2020 after COVID-19 demand high quality protection in all arena of life. The most important arena have been elaborated below.

\section{THE NEED FOR COMMUNITY PSYCHOLOGY AND TRANSFORMATIVE CHANGE IN MENTAL HEALTH SERVICES}

Despite the high ratio of mental health issues in Pakistan, the mental health services and treatment moda- lities are very low. According to recent data, currently, three formal and informal sources are available for mental health delivery in Pakistan (Ali \& Gul 2018). Formal sectors include community-based services and public sector based services that facilitate patients through Non-Governmental Organizations (NGOs) and Public psychiatric units (Ali \& Gul 2018). As far as hospital-based mental services are concerned only 480 psychologists and 520 certified psychiatrists are available in Pakistan (World Health Organization 2009). In addition, informal health services comprised of religious and faith healers. The informal mental health healing services delivery is also considered effective due to low cost and lack of social stigmatizations.

The high mental health issues and low mental health services in Pakistan are not sufficient to control the mental health problem ratio. In particular, the condition has turned more worst after the COVID-19 pandemic. There is a need to develop more mental health services to facilitate mental health patients and the community (Walker et al. 2017). Also, there is a dire need to transform mental health services considering the advanced needs of the current time. The transformative changes are not merely limited to types of services available to patients or populations, but also indulge community support, social conditions (employment, housing), social policies, and research. Community Psychology is unique to promote transformative change. In Pakistan, the stigmatization of mental illness is still unacceptable, and communities do not support mental health patients. 
Community psychology must be intact while delivering mental health services for several reasons. Firstly, Community psychology focuses on the importance of values considering the patient-centered approach. These values include compassion, caring, self-determination, social justice, and respect for diversity (Nelson et al. 2020). Secondly, community psychology focuses on the social context and ecological perspective to keep a balance between individuals and the environment. Thirdly, community psychology emphasizes citizen partnership and empowerment. The metal health services must be intact considering the values, social context, empowerment, and other socio-psychological aspect of the community (Murphy et al. 2020). In addition, considering the current need of the community, the emental health approach and digital psychiatry must be included in the community services to facilitate the people. The outbreak of COVID-19 created a poor quality of housing. Lack of employment opportunities and social isolation are affecting community fabric as a whole. All the people of the community experience similar mental health issues; therefore understating the community psychology an advanced version of metal health support is needed. During the $19^{\text {th }}$ and early $20^{\text {th }}$ century, the motive of mental health services was to search for justice. Hence during the last 35 years the aim of mental health services transformed into policy deliberations (Murphy et al. 2020).

Hence the community psychology can better help in developing transformative changes in society. The transformative changes considered second-order change as the focus entails the fundamental alteration in the operation of systems and values (Rothan \& Byrareddy 2020). For example, the patient with a mental health issue is a respectable citizen with potentials, rights, and strengths for recovery. Most specifically the transformative changes in intervention, counselor or psychologist role, and desired outcomes are more imperative in the critical time of the COVID-19 outbreak. As ameliorative changes follow the individualistic model, so it can be assumed that all the code of ethics and code of conduct will be intact (Mukhtar 2020).

Community psychology and community mental health services have been very effective throughout human history. During natural and man-made disasters, the role of psychologists, psychiatrists, and mental health professionals has been very impressive (Imran et al. 2020). The implications of community psychology and community mental health services transformations according to the current need of time would be an effective step to maintain fabric in society.

\section{THE NEED FOR ONLINE MENTAL HEALTH SERVICE}

The second lessons that have been learned during COVID-19 are to develop online therapeutic interventions (Rehman \& Lela 2020). Regardless of physical illness, the COVOD-19 is imparting a substantial negative impact on the mental health of the people. The contemporary intervention approaches are mandatory to manage the devastating effects of COVID-19 (Alvi \& Omrani 2019). As mental health patients are prevailing on a large scale, but the population cannot access mental health care due to limited geographical location and quarantine (Mukhtar 2020). Therefore, the need for availing the ever-increasing proliferation of e-mental health approaches in bridging the treatment gap has been observed (Alvi \& Omrani 2019). It stressed upon the formulation of mental health response to combat against unique elements of a pandemic outbreak.

Online cognitive behavior therapy is a new approach in the mental health approach which proposes effective management within 12 steps following an asynchronous format (Alvi \& Omrani 2019). Online cognitive behavior therapy should be offered in the form of an online course. According to Alvi \& Omrani (2019), the twelve steps of the e-CBT model are a) What are depression and anxiety? b) What is the five-part model? c) The connection between thought, feeling and behavior, environment, and physical behavior, d) Strategies to deal with anxiety, depression or stressful situation, e) Understanding and rating our feelings and thoughts record, f) What are automatic thoughts? g) Activity scheduling, h) what is evidence and how can it help us rate our thoughts and feelings? h) What is alternative and balanced thinking? I) Experiment on alternative thoughts, j) Action plan, and k) Review. Apart from e-CBT, other e-mental health services were also found to be effective during COVID-19. According to Liu et al., (2020) the e-mental health education through WeChat, TikTok, and Weibo were found to be effective for the management of mental health issue. Furthermore, a majority of the Pakistani population is illiterate, therefore the psychologists should provide proper assistance to patients regarding the need and implementation of appropriate mental health plan for making future life peaceful.

\section{NEED FOR RESEARCH ARCHIVE AT NATIONAL LEVEL}

According to literature, Pakistan encountered more challenges to control the impact of COVID-19 compared to China, the European Union Nation, and Iran (Ilyas et al. 2020). Pakistan faced more challenges as it is the most populated country with low income per capita estimated the US \$45 during 2015-2016 (Pakistan Bureau of Statistics 2020). The economic condition of Pakistan is very important in controlling the adverse impact of COVID-19 (Chaudhry et al. 2020). As the pharmacy services in Pakistan are not capable to meet the international standards to provide patient care. The researchers are needed to investigate the fractures and gaps in social, economical and health care systems, which are imparting the devastating impact on the overall growth of the country. According to literature, Drug Regularity Authority of Pakistan (2012) impose multiple obligations to the pharmacist, but unfortu- 
nately, the number of pharmacy store are very few including with few services such as distribution, storage, management and dispensing (Atif et al. 2020). Apart from Low availability of pharmacy services, literature suggested that mounting threat with the optimal medication error, misuse of a controlled substance, adverse drug reaction and medication-related mal-practices (i.e. unsafe storage, medicine prescription, poor availability of medicine and disposal of medicine) (Atif et al. 2020). During the COVID-19 full-blown pharmacy services are needed to adhere to the recommended preventative measures against COVID-19 (Atif et al. 2020). The government should provide an interest-free loan to graduate or postgraduate students to open their pharmacy stores. More researches are needed to investigate the nature and level of misconduct in pharmacy and related health care services. Whatever advancement and progress Pakistan can make, is purely dependent on scholarly work or scientific researches (Haleem et al. 2020). Furthermore, a majority of the Pakistani population is illiterate, therefore the pharmacist should provide proper assistance to patients regarding the usage, dosage, and identification of appropriate medication (Atif \& Malik 2020). Empirical researches and evidenced-based researches must be carried out to investigate the mal-practices of medication so that strict action can be taken to reduce such medication errors. The practical implementation of knowledge in every field of education provides the solution for every problem; therefore the role of research is very crucial. As mentioned earlier the impact of COVID-19 is not limited to physical illness, but also interlinked with mental issues as well. According to recent data COVID-19 is associated with depression, anxiety, personality disorder, drug abuse, and suicide (Chen et al. 2020, Dubey et al. 2020). The psychologist, counselors, and mental health practitioner's timely efforts are very much needed to reduce the ratio of mental issues that emerged during COVID-19 (Mamun \& Ullah 2020). Again there is a dire need to conduct researches to assess the nature and level of mental health issues so that an advanced intervention plan can be designed to mitigate it (Clerici et al 2020). Hence, policy formulation, emergency preparedness, surveillance, thermal screening, test tracking, diagnosing, and testing tools can be improved only through researches or scholarly work (Haleem et al. 2020). Mishandling of pilgrim without proper screening resulted in the slippage of the virus in the country (Noreen et al 2020). The high influx of infection in the poor province of Pakistan leads to much mental and physical illness, while the healthcare facilities were understaffed or under-resourced (Faiz 2020). More evidence-based researches are needed for the assessment as well as management of COVID-19 impact. During quarantine, the lack of income, time, and funding are the core reasons that have crumbled in conducting the latest researches. Hence, at this time the need for scholarly work and the latest research is very important to conduct. Through researches, unprecedented steps can be taken to mitigate the devastating effects of COVID-19. Countrywide mental health policy is required to deal with such expected and unexpected challenges in future.

\section{THE NEED FOR CHANGES IN PROVISION OF MENTAL HEALTH SERVICES TO CHILDREN}

The Coronavirus disease (COVID-19) profoundly affected the world on a high scale. People of all ages experienced physical as well as mental health issues. In particular, the children were found to be on the potential risk of mental health issues (Imran et al. 2020). The need for mental health issues for children is a key area that needs considerable attention after pandemic or crises.

\section{PRACTICAL CHALLENGES IN CHILD PSYCHIATRY}

\section{Phase 1.}

During the preparation phase, it is important to provide accurate information to patients and parents regarding post-pandemic conditions. Authentic and accurate information about post-pandemic conditions and compliance with the precautionary measure is important. The children must be well-informed about the possible challenge, risk, and consequences of COVID-19. Furthermore how of adapt in the changed daily routine life during social distancing and school closure can also help mitigate the obnoxious consequences. The parent or societal support for children on how to manage depression and anxiety symptoms during COVID-19 is also very crucial in developing positive consequences (The Alliance for Child Protection in Humanitarian Action 2020). The parent should stock recommended medication prescribed by doctors to their children during the phases of the pandemic, it is not life hoarding, but a precautionary measure to avoid any obnoxious consequences for chronically ill patients. Furthermore, in the preparation phase telepsychiatry must be considered as an existing body of research that provides the huge effectiveness of online psychotherapeutic interventions (Rehman \& Lela 2020)

\section{Phase 2. (Punctum Phase)}

Children need psychiatric and mental health services throughout all the phases of a pandemic. Children with psychiatric or psychological illnesses including severe conditions such as autism suffered from significant distress due to lack of psychiatric support. Due to the closure of psychiatric, mental health, and educational settings for children with developmental delays, their problems have exacerbated (Imran et al. 2020). Mental health services, educational settings, and psychiatric settings must keep contact with the children through internet-based interventions to avoid the disruptions in treatment modalities. The severity of mental health issues worsens due to delay in diagnosis, prognosis, and implementation of the management plan. Psychological intervention for children must be present all the time 
prior, during, and after the pandemic. The psychological intervention during a pandemic should not be limited to children with existing mental health issues but to all those who are at risk or more vulnerable to developing depression, anxiety, and stress (Dalton et al. 2020). Another sensitive issue during the acute phase of the pandemic is inpatient isolation from parents and other family members. The complete disconnect from family for safety purposes can leave devastating effects in terms of anxiety, stress, and depression. Hence, digital communication must be arranged for psychiatric or parental contact. Child psychiatry, mental health assistance, or psychological support can be enhanced by providing trainees to health care staff. For those purposes, the innovative didactic techniques such as online supervision and training, web-based programs, video presentations for developing formative activities can be used.

\section{Phase 3 (Back to normality)}

In the third and last phase of the pandemic, it is mandatory to re-establishing and reorganizing the lost list of treatment to deal with the burden and strain of patients. In several countries, the emergencies have been addressed during the pandemic. It is not limited to psychological, medical, or mental health aid, but also includes child protection services. According to literature, not only the acute phase of the pandemic are important to address, rather services aftermath of a pandemic is very crucial to mitigate the long term effects. The consequences of economic crises during and after the pandemic can be seen in terms of domestic violence, family conflict, child abuse, and substance abuse (Vigerland et al. 2020). Access to advance mental health services are crucial to controlling the effects of pandemic aftermath impact. Substantial data suggested a decline in the use of mental health services. Hence a surge of activity must be initiated to reduce the impact of COVID-19. During the pandemic phase, the victim of child abuse, neglect, and other child maltreatment have been ignored due to lack of research, peer or social support Children's mental health services must be provided to children. Mental health practitioners and psychiatrists must be aware of the high ratio of maltreatment during COVID-19. Frequent diagnoses for a suspicious condition must be made to reduce the risk of maltreatment.

\section{CONCLUSION}

The study has contemporary significance as disasters, crises and communicable disease has been prevalent throughout human history and may attack the world at any time in the future. The preparedness in terms of medical, social, psychological, and community levels is imperative for mitigating the post pandemic effects.

\section{Take Home Message and Future Directions}

- The current study highlights the new direction to adjust or reorganize the world of 2020 after COVID19 outbreak.
- The current study focused on a few arenas of life such as need for transformative changes in mental health support, scholarly work, mental health support to children's and need for digital psychological support or internet based interventions. Moreover, the study findings provide directions for future researchers to consider more important life arena's that need considerable attention after COVID-19 outbreaks. In this way more issues can be resolved to maintain fabric in the society.

- The current study also threw lights how the researcher, psychologists, psychiatrist and mental health practitioner should find out the fracture and gaps in the society to improve the adverse condition prior and after the communicable disease. However, the preparedness prior to any communicable outbreak ameliorate better consequences.

\section{Acknowledgements:}

Author would like to thank Dr. Ume Laila, Assistant Professor and Head of Department at GIFT University Pakistan for her guidance, encouragement and assistance in keeping our progress on schedule. Furthermore, a special thanks to GIFT University for collaborating together in research to carry out the study.

\section{Conflict of interest: None to declare.}

\section{Contribution of individual authors:}

All authors reviewed and discussed the manuscript draft and contributed to the final manuscript. All authors give final approval of the version to be submitted.

\section{References}

1. Ali MA \& Gul S: Community Mental Health Services in Pakistan: Review study of Muslim World 2000-2015. Psychology, Community and Health 2018; 7:57-71. doi:10.5964/pch.v7i1.224

2. Alvi, N. Omrani, M: Online cognitive behaviour therapy: An e-mental health approach to depression and anxiety. Springer Nature Switzerland, 2020

3. Atif M, Malik I, Asif M, et al.: Drug safety in Pakistan. In: Al-Worafi $Y$, editor. Drug safety in developing countries: achievements and challenges. India: Elsevier 2020; 287-316

4. Atif M, Razzaq W, Mushtaq I, Malik I, et al.: Pharmacy services beyond the basics: a qualitative study to explore perspectives of pharmacists towards basic and enhanced pharmacy services in Pakistan. Int $J$ Environ Res Public Health 2020; 17:2379

5. Atif $M$ \& Malik I: COVID-19 and community pharmacy services in Pakistan: challenges, barriers and solution for progress. Journal of pharmaceutical policy and practice 2020; 13:33. https://doi.org/10.1186/s40545-020-00240-4

6. Chaudhry RM, Hanif A, Chaudhary M et al.: Coronavirus Disease 2019 (COVID-19): Forecast of an Emerging Urgency in Pakistan. Cureus 2020; 12:e8346. https://doi.org/10.7759/cureus.8346 
7. Chen F, Zheng D, Liu J, Gong Y, Guan Z \& Lou D: Depression and anxiety among adolescents during COVID-19: A cross-sectional study. Brain, behavior, and immunity. S0889-1591(20)30891-6. Advance online publication 2020. https://doi.org/10.1016/j.bbi.2020.05.061

8. Clerici CA, Massimino $M \&$ Ferrari A: On the clinical psychologist's role in the time of COVID-19, with particular reference to experience gained in pediatric oncology. Psycho-oncology, 2020.

https://doi.org/10.1002/pon.5418

9. Dalton L, Rapa E, Stein A: Protecting the psychological health of through effective communication about COVID19. Lancet Child Adolesc Health, 2020. doi:10.1016/S2352-4642(20)30097-3 4

10. Dubey MJ, Ghosh R, Chatterjee S, et al.: COVID-19 and addiction. Diabetes \& metabolic syndrome. 2020; 14:817823. Advance online publication. https://doi.org/10.1016/j.dsx.2020.06.008

11. Faiz B: Health and healthcare in Balochistan. 2020; 1-6. Available from: https://www.thefridaytimes.com/healthand-healthcare-in-balochistan/

12. Government of Pakistan: Ministry of Planning, Development \& Special Initiatives; Pakistan Bureau of Statistics. Pakistan Statistical Year Book 2018 (Provisional). http://www.pbs.gov.pk/sites/default/files//PAKISTAN\%20S TATISTICAL\%20YEAR\%20BOOK\%202018.pdf. Accessed March 16, 2020

13. Haleem A, Javaid M, Vaishya R, et al.: Areas of academic research with the impact of COVID-19. The American journal of emergency medicine 2020; 38:1524-1526. https://doi.org/10.1016/j.ajem.2020.04.022

14. Imran $N$, Zeshan $M$ \& Pervaiz Z: Mental health considerations for children \& adolescents in COVID-19 Pandemic. Pakistan journal of medical sciences 2020; 36(COVID19-S4):S67-S72. https://doi.org/10.12669/pjms.36.COVID19-S4.2759

15. Ilyas N, Azuine RE, Tamiz A: COVID-19 pandemic in Pakistan. International Journal of Translation Medical Research and Public Research 2020; 4:37-49

16. Liu JJ, Bao Y, Huang X, Shi J, Lu L: Mental health considerations for children quarantined because of COVID-19. Lancet Child \& Adolesc Health, 2020. doi:10.1016/S23524642(20)30096-1

17. Mamun MA, Ullah I: COVID-19 suicides in Pakistan, dying off not COVID-19 fear but poverty? - The forthcoming economic challenges for a developing country. Brain Behav Immun 2020; 87:163-166. doi:10.1016/j.bbi.2020.05.028

18. Mukhtar S: Mental Health and Psychosocial Aspects of Coronavirus Outbreak in Pakistan: Psychological Intervention for Public Mental Health Crisis [published online ahead of print, 2020 Apr 16]. Asian J Psychiatr 2020; 51:102069. doi:10.1016/j.ajp.2020.102069

19. Murphy R, Calugi S, Cooper Z, et al.: Challenges and opportunities for enhanced cognitive behaviour therapy (CBT-E) in light of COVID-19. Cognitive Behaviour Therapist 2020; 13:e14.

https://doi.org/10.1017/S1754470X20000161

20. Nelson G, Kloos B, Ornelas J: Community psychology and community mental health towards transformative change. Oxford University Press, 2020

21. Noreen N, Dil S, Niazin SU, Naveed I, et al.: D. COVID 19 Pandemic \& Pakistan; Limitations and Gaps. Global Biosecurity 2020; 1. doi:http://doi.org/10.31646/gbio.63

22. Pakistan Bureau of Statistics: National Health Accounts of Pakistan, 2015-2016. 2018. http://www.pbs.gov.pk/sites/ default/files//NHA-Pakistan\%202015-16\%20Report_0.pdf. Accessed 14 Oct 2018.

23. Rehman, S, Lela U: Psychological aid to COVID-19: A Mental Health Response to Crises Management. Psychiatria Sanubina 2020; 32:145-150

24. Rothan HA \& Byrareddy SN: The epidemiology and pathogenesis of coronavirus disease (COVID-19) outbreak. Journal of Autoimmunity 2020; 109:102433. https://doi.org/10.1016/j.jaut.2020.102433

25. The Alliance for Child Protection in Humanitarian Action: Technical Note: Protection of Children during the Coronavirus Pandemic (v.1); 2020. https://alliancecpha.org/en/COVD19

26. Vigerland S, Lenhard F, Bonnert M, Lalouni M, Hedman $E$, Ahlen $J$, et al.: Internet-delivered cognitive behavior therapy for children and adolescents: a systematic review and meta-analysis. Clin Psychol Rev 2016; 50:1-10

27. Waris A, Atta UK, Ali M, Asmat A, et al.: COVID-19 outbreak: current scenario of Pakistan. New microbes New Infections. 2020; 35. https://doi.org/10.1016/j.nmni.2020.100681

28. World Health Organization: Coronavirus disease 2019 (COVID-19), Situation Report-80. https://www.who.int/ docs/default-source/coronaviruse/situation-reports/ 20200409-sitrep-80-covid-19.pdf?sfvrsn=1b685d64_6. Published April 9, 2020. Accessed April 10, 2020

29. World Health Organization: Mental health system in Pakistan (WHO-AIMS report), 2009. Retrieved from http://www.who.int/mentalhealth/pakistanwhoaimsreport.pdf

30. Walker C, Hart A \& Hanna P: Building a new community psychology of mental health: Spaces, places, people and activities. Basingstoke: Palgrave Macmillan, 2017

31. Worldometer. (n.d.). Current world population. Retrieved July 17, 2020. from https://www.worldometers.info/ coronavirus/country/pakistan/

Correspondence:

Sana Rehman, MD

Humanities and Social Sciences Department, GIFT University

Sialkot Bypass, Lohian Wala, Gujranwala, Punjab 52250, Pakistan

E-mail: sanarehmanpk@gmail.com 